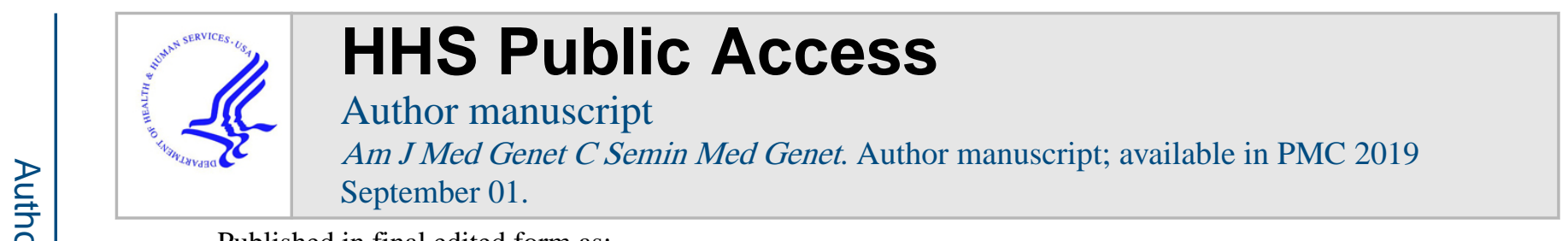

Published in final edited form as:

Am J Med Genet C Semin Med Genet. 2018 September ; 178(3): 326-337. doi:10.1002/ajmg.c.31638.

\title{
Pulmonary Manifestations in Tuberous Sclerosis Complex
}

\author{
Nishant Gupta ${ }^{1}$ and Elizabeth P. Henske ${ }^{2}$ \\ ${ }^{1}$ Division of Pulmonary, Critical Care and Sleep Medicine, University of Cincinnati, Cincinnati $\mathrm{OH}$ \\ 2Department of Medicine, Brigham and Women's Hospital and Harvard Medical School, Boston, \\ MA
}

\begin{abstract}
Tuberous sclerosis complex has manifestations in many organ systems, including brain, heart, kidney, skin, and lung. The primary manifestations in the lung are lymphangioleiomyomatosis (LAM) and multifocal micronodular pneumocyte hyperplasia (MMPH). LAM affects almost exclusively women, and causes cystic lung destruction, pneumothorax, and chylous pleural effusions. LAM can lead to dyspnea, oxygen dependence, and respiratory failure, with more rapid disease progression during the premenopausal years. In contrast, MMPH affects men and women equally, causing small nodular pulmonary deposits of type II pneumocytes that rarely progress to symptomatic disease. Here, we review the clinical features and pathogenesis of LAM and MMPH.
\end{abstract}

\section{Keywords}

TSC; Lymphangioleiomyomatosis (LAM); Sirolimus; mTOR; VEGF-D

\section{Introduction}

Tuberous sclerosis complex (TSC) is an autosomal dominant multisystemic disorder characterized by the formation of hamartomas and dysplastic lesions in various organs such as skin, heart, kidneys, brain, and lungs (Henske, Jozwiak, Kingswood, Sampson, \& Thiele, 2016). In this chapter, we will provide an overview of the pulmonary manifestations that can be associated with TSC.

\section{Lymphangioleiomyomatosis (LAM)}

Genetics-TSC is caused by germline, loss-of-function mutations in the TSC1 gene on chromosome 9q34 or the TSC2 gene on chromosome 16p13 (Dabora et al., 2001; Henske et al., 2016; Jones et al., 1999). Women with both TSC1 and TSC2 mutations can develop LAM. Rare cases of LAM have also been reported in men with TSC, including at least two cases of biopsy-proven LAM in men with germline TSC2 mutations and a male XY karyotype (Adriaensen, Schaefer-Prokop, Duyndam, Zonnenberg, \& Prokop, 2011; Aubry et

Corresponding Author: Nishant Gupta, MD, MS, Division of Pulmonary, Critical Care and Sleep Medicine, University of Cincinnati, 231 Albert Sabin Way, MSB Room 6053, ML 0564, Cincinnati, OH 45267, Phone: 513-558-4831, Fax: 513-558-4858, guptans@ucmail.uc.edu.

Conflicts of Interest: The authors declare no conflicts of interest. 
al., 2000; Henske et al., 1997; Kim, Chung, Park, Lee, \& Han, 2003; Miyake et al., 2005; Ryu, Sykes, Lee, \& Burger, 2012; Schiavina et al., 2007).

LAM is characterized histopathologically by the diffuse, bilateral proliferation of smooth muscle like cells that express melanocyte lineage markers including gp100.

Immunoreactivity with the HMB-45 antibody, which recognizes gp100, is the gold standard for the pathologic diagnosis of LAM (Figure 1). These so-called LAM cells exist within microscopic nodules that contain other cell types, including lymphatic vessels and lymphocytes. As with other tumor suppressor gene syndromes, inactivation of both alleles of $T S C 1$ or TSC2 is believed to be required for the initiation of LAM. Inactivation of the remaining wild-type copy of TSC1/TSC2 has been found in micro-dissected LAM cells from women with TSC-associated LAM (which will be referred to as TSC-LAM). This inactivation is usually the loss of the chromosomal region that includes the remaining wildtype copy of TSC1 or TSC2 (J. Yu, Astrinidis, \& Henske, 2001), which is termed "loss of heterozygosity" since the germline mutant allele is now present in a homozygous form, vs. a heterozygous form when both the mutant and wild-type alleles are present.

In general, TSC2 mutations cause more severe clinical disease than TSC1 mutations; this is true in the brain and kidney and also true for LAM (Dabora et al., 2001). However, it is important to emphasize that severe TSC manifestations can occur in TSC1 patients. There is considerable variability between patients in terms of the spectrum and severity of manifestations, even among members of the same family (carrying the same germline mutation). The reasons for this phenotypic variation are incompletely understood, but are believed to include the "chance" nature of the somatic second hit genetic events that initiate tumors of the brain, skin, and kidney and that initiate LAM pathogenesis. Germline inactivating mutations throughout the TSC2 gene are associated with LAM (Strizheva et al., 2001).

In addition to TSC-LAM, LAM occurs in women who do not have clinical evidence of TSC on physical exam or by imaging of the brain and kidneys; this is referred to as sporadic LAM. Women with sporadic LAM do not have germline $T S C$ gene mutations (Astrinidis et al., 2000) and do not appear to have a risk of genetic transmission of TSC or LAM. A breakthrough in understanding the pathogenesis of sporadic LAM occurred in 2000, with the detection of inactivating TSC2 gene mutations in micro-dissected LAM cells from four sporadic LAM patients who also had angiomyolipomas (AMLs) (Carsillo, Astrinidis, \& Henske, 2000). As expected, because these were cases of sporadic LAM, these mutations were not present in peripheral blood lymphocytes or in histologically normal lung.

Subsequent work confirmed the presence of TSC2 mutations in cells cultured from the lungs of women with LAM obtained at the time of lung transplantation (Goncharova et al., 2002) and in micro-dissected LAM nodules (Badri et al., 2013). Interestingly, this most recent study found that the percentage of the TSC2 mutant allele within the LAM nodules is small, with nine different somatic mutations detected in eight sporadic LAM samples at frequencies ranging from $4-60 \%$, but mostly under $20 \%$. These results indicate that LAM nodules are heterogeneous, containing both TSC 2 wild type and TSC2 mutant cells, with the wild-type cells being significantly more numerous than the mutant cells. Currently, our knowledge about these other cell types, and their roles in LAM pathogenesis, is somewhat 
limited, although recent work is beginning to unravel the immune microenvironment of LAM (Liu et al., 2018; Osterburg et al., 2016).

Angiomyolipomas (AMLs) are benign tumors that most often occur in kidney, although they can also be found in the liver and other organs. As their name suggests, AMLs are composed of abnormal vascular structures, smooth muscle cells, and fat. Genetic studies have shown that all three of these cellular elements carry somatic "second hit' genetic events (Karbowniczek, Yu, \& Henske, 2003; Niida et al., 2001), illustrating remarkable differentiation plasticity. The smooth muscle cells within AMLs are virtually identical to LAM cells, with both expressing smooth muscle and melanocyte lineage markers, as well as estrogen and progesterone receptor.

AMLs occur in approximately one-third of women with the sporadic form of LAM, who do not have germline TSC gene mutations (Ryu et al., 2006). These AMLs appear to be identical to the AMLs that occur in TSC. Remarkably, in the study of women with sporadic LAM discussed above, identical somatic mutations in the TSC2 gene were found in microdissected LAM cells and in AML tissue. These mutations were not present in normal tissue, including normal kidney tissue. This finding led to the "benign metastasis" hypothesis that LAM cells arise outside the lung, and transfer or metastasize to the lung (Henske, 2003). Consistent with this hypothesis, analysis of two women in whom LAM recurred after lung transplantation has revealed that the same TSC2 mutation is present in LAM cells before and after transplantation (Karbowniczek, Astrinidis, et al., 2003). In addition, LAM cells with loss of heterozygosity in the TSC2 gene region of chromosome $16 \mathrm{p} 13$ have been detected in the circulation of women with LAM, suggesting that LAM cells are migrating through the blood circulation (as well as presumably through the lymphatic circulation). The presence of circulating LAM cells is decreased after rapamycin/sirolimus therapy (Cai et al., 2014; Harari et al., 2016).

The genetic basis of multinodular multifocal pneumocyte hyperplasia (MMPH) is less well understood than the genetics of LAM. MMPH occurs in both men and women with TSC, at equal frequency and high prevalence, as will be discussed later. Whether or not "second hit" mutational events inactivating the remaining wild-type copy of TSC2 occur in the pneumocytes within MMPH lesions is not known.

Pathogenesis-As discussed above, one theory for LAM pathogenesis postulates that LAM cells arise outside the lung. LAM has been thus described as a "low grade metastasizing neoplasm" (McCormack, Travis, Colby, Henske, \& Moss, 2012). There are at least three critical questions that arise from this model: 1) Where do LAM cells arise? 2) Why does LAM occur almost exclusively in women? 3) How do LAM cells cause cystic lung destruction?

Where do LAM cells arise?: The cellular origin of LAM cells is the topic of a great deal of speculation, and very little data. It has been proposed, based in part on elegant mouse models and pathologic findings, that LAM cells may arise in the uterus (Prizant et al., 2013; Suzuki et al., 2016). Other possibilities include embryonic stem cells, kidney epithelial cells, lymphatic endothelial cells, and neural crest cells (Henske \& McCormack, 2012). Among 
many attempts to genetically engineer mice to develop LAM, the closest example so far is the inactivation of TSC2 in the mouse uterus (Prizant et al., 2013). These uterine-specific Tsc2 knockout mice develop progressive uterine enlargement and myometrial overgrowth starting at 6-12 weeks, with leiomyomas forming by 24 weeks of age. Older Tsc2 uterinespecific knockout females develop Tsc2 null myometrial tumors in the lungs, suggesting that lung LAM-like myometrial lesions may indeed originate from the uterus. Rapamycin or ovariectomy in these mice prevents myometrial overgrowth.

Why does LAM occur almost exclusively in women?: LAM cells express estrogen receptor alpha and progesterone receptor (Logginidou, Ao, Russo, \& Henske, 2000). Potential hypotheses for the gender imbalance of LAM include the possibility that LAM cells, in most cases, arise from the uterus, and that the proliferation and metastasis of LAM is potentiated by female hormones such as E2. Data supportive of these hypotheses include that in the uterine-specific tsc 2 knock out model, treatment of ovariectomized mice with estrogen restored abnormal uterine growth, and in subcutaneous models in which mice carrying Tsc2-deficient tumors are treated with E2, the incidence of pulmonary metastases is increased (J. J. Yu et al., 2009). The estrogen receptor antagonist Faslodex can decrease the E2-driven MMP2 upregulation and block lung metastases, thus enhancing survival of E2treated mice bearing xenograft tumors of TSC-2 deficient cells (Li et al., 2013). In vitro, treatment of Tsc2-deficient cells with E2 can activate MEK/ERK signaling networks (J. Yu, Astrinidis, Howard, \& Henske, 2004; J. J. Yu et al., 2009).

How do LAM cells cause cystic lung destruction?: A leading hypothesis is that LAM cells make and secrete proteases or other enzymes that degrade the surrounding lung parenchyma. LAM cells characteristically express Cathepsin K by immunohistochemistry (Chilosi et al., 2009), leading to the hypothesis that Cathepsin $\mathrm{K}$, a cysteine protease, could be involved in matrix destruction. Recently Cathepsin K expression in the LAM nodule was shown to be dependent on the interactions between LAM cells- and LAM associated fibroblasts, with TSC2 deficient cells playing a role in reducing the $\mathrm{pH}$, a necessary condition for Cathepsin K protease activation (Dongre, Clements, Fisher, \& Johnson, 2017). TSC2-deficient cells have also been found to express matrix metalloproteinases (MMPs) including MMP2 and MMP9 (Matsui et al., 2000; Moses, Harper, \& Folkman, 2006). In mouse models, treatment with estradiol increases MMP2 levels, and induces extracellular matrix remodeling with a reduction of Type IV collagen deposition, both of which can be blocked by the estrogen antagonist Faslodex (Li et al., 2013). These data led to the concept that treatment with Doxycycline, a MMP inhibitor, might stabilize lung function in LAM (Moses et al., 2006). Unfortunately, a randomized, placebo controlled, double-blind clinical trial failed to find benefit from Doxycycline in LAM patients (Chang et al., 2014).

Epidemiology - While the exact incidence and prevalence of LAM remain largely undefined, current estimates suggest a worldwide prevalence of 3.4-7.8 per million women (Harknett et al., 2011). Extrapolating these numbers to the current world population would suggest a worldwide case burden ranging between approximately 13,000 - 30,000 women with LAM. These numbers are likely an underestimate of the actual disease prevalence as a large proportion of patients with LAM remain either undiagnosed or misdiagnosed. 
Although Caucasians and Asians tend to be over-represented in the LAM literature, this discrepancy in ethnic and racial diversity is likely based on divergent access to healthcare resources rather than a true racial predilection for whites and Asians. Even though the estimated number of TSC-LAM patients far exceeds the sporadic LAM group, sporadic LAM patients form the majority (80-90\%) of the clientele at adult pulmonary clinics. Potential explanations for this paradox include milder disease burden in TSC patients as compared to sporadic LAM patients, or prioritization of other medical issues in the TSC population (N. Gupta, Vassallo, Wikenheiser-Brokamp, \& McCormack, 2015).

Clinical Manifestations-The three major modes of presentation for patients with sporadic LAM include dyspnea on exertion, spontaneous pneumothorax, or incidental discovery due to imaging performed for other indications (Oprescu, McCormack, Byrnes, \& Kinder, 2013). The mean age at diagnosis of LAM is about 35 years (N. Gupta, Vassallo, et al., 2015). In contrast, most patients with TSC are diagnosed with LAM at an earlier stage due to active case screening. However, adulthood diagnosis of TSC is not uncommon, and LAM may be the presenting manifestation of underlying TSC (Taveira-DaSilva et al., 2015). As such, it is important to perform a detailed history and physical examination to search for the presence of TSC in all patients with LAM (N. Gupta, Finlay, et al., 2017). Table 1 highlights the salient differences in the clinical manifestations of TSC and sporadic LAM.

Dyspnea on exertion is the most common symptom experienced by LAM patients. Other less frequent signs and symptoms of LAM commonly experienced by the patients include fatigue, chest pain, cough, and symptoms related to chylous congestion either manifesting as chyloptysis or chylous fluid collections in the thoracic or abdominal cavities (Ryu et al., 2006). Exogenous estrogen use (Yano, 2002) and pregnancy (Yockey, Riepe, \& Ryan, 1986) have been reported to accelerate the disease course in LAM, and disease diagnosis during or immediately following pregnancy is not uncommon (Cohen, Freyer, \& Johnson, 2009; Urban et al., 1999). In some patients, the diagnosis may come to light due to non-pulmonary reasons, most commonly related to spontaneous hemorrhage into renal AMLs presenting as severe flank pain, hypotension, and/or anemia.

LAM patients are often misdiagnosed as asthma or chronic obstructive pulmonary disease, leading to a 3-5 year delay between symptom-onset and disease diagnosis (Urban et al., 1999). Similarly, young females presenting with a spontaneous pneumothorax are often labeled as primary spontaneous pneumothorax and alternate etiologies are not searched until they have had a recurrent event (Almoosa et al., 2006). A recent study has shown that performing a screening high-resolution computed tomography (HRCT) among patients presenting with an apparent primary spontaneous pneumothorax is cost-effective, and can help in alleviating the delay in diagnosis for at least a proportion of LAM patients (N. Gupta, Langenderfer, McCormack, Schauer, \& Eckman, 2017).

Diagnosis-The mainstay of establishing the diagnosis of LAM relies on the detection of characteristic cystic abnormalities on HRCT of the chest. Characteristic LAM cysts on HRCT are thin-walled, round, uniform, and are present bilaterally in a diffuse distribution (Figure 1) (N. Gupta, Meraj, et al., 2015; Johnson et al., 2010). Characteristic HRCT findings alone, however, are not enough to establish a confirmed diagnosis of LAM (N. 
Gupta, Finlay, et al., 2017). In patients with TSC, the presence of characteristic cysts on HRCT is considered compatible with a clinical diagnosis of LAM. Other features that can complement the HRCT findings and help establish a confirmed diagnosis of LAM include: 1) presence of renal AMLs, 2) elevated serum vascular endothelial growth factor-D (VEGFD) greater than $800 \mathrm{pg} / \mathrm{ml}, 3$ ) chylous effusions, or 4) lymphangioleiomyomas (N. Gupta, Finlay, et al., 2017). In the absence of one of the above confirmatory features, histopathological diagnosis of LAM may need to be established by a lung biopsy (N. Gupta, Finlay, et al., 2017).

Screening \& Surveillance-The prevalence of LAM among females with TSC has been variably reported to range between 26-49\% (Costello, Hartman, \& Ryu, 2000; Cudzilo et al., 2013; Franz et al., 2001; Moss et al., 2001; Muzykewicz et al., 2009). The probability of developing LAM in females with TSC is age-dependent and increases by $8 \%$ every year (Cudzilo et al., 2013). In the study by Cudzilo et al., the prevalence of LAM was 27\% in females with TSC aged less than 21 years, and progressively increased to a prevalence of $81 \%$ in females older than 40 years of age (Cudzilo et al., 2013).

Due to the high prevalence of LAM in females with TSC, it is recommended to obtain a screening HRCT in adult females with TSC at the age of 18 years (Johnson et al., 2010; Krueger, Northrup, \& International Tuberous Sclerosis Complex Consensus, 2013). The frequency and timing of repeat CT scans after the first scan at 18 years is less well established. The European Respiratory Society (ERS) guidelines suggest performing a repeat HRCT at the age of 30 years, if the initial screening $\mathrm{CT}$ at 18 years was negative (Johnson et al., 2010). The International TSC Consensus Group recommends a repeat HRCT 5-10 years after the screening CT, in the event that the initial screening CT was negative (Krueger et al., 2013). History regarding common pulmonary symptoms of dyspnea and cough should be obtained from all adults with TSC at each visit. Patients with evidence of LAM on the screening CT chest should be monitored with annual pulmonary function tests (PFTs) and periodic HRCT every 2-3 years (Krueger et al., 2013).

Natural History and Prognosis-The natural history of LAM is characterized by progressive decline in lung function, and if left untreated, ultimately leads to severe respiratory insufficiency and death (Johnson \& Tattersfield, 2000; Johnson, Whale, Hubbard, Lewis, \& Tattersfield, 2004). The rate of decline of forced expiratory volume in one-second (FEV1) in LAM has been reported to vary between $47-134$ ml/year (Chang et al., 2014; Hayashida et al., 2016; McCormack et al., 2011; Taveira-DaSilva, Stylianou, Hedin, Hathaway, \& Moss, 2004), and is influenced by several factors including baseline disease severity (Hayashida et al., 2016), menopausal status (Johnson \& Tattersfield, 1999; TaveiraDaSilva et al., 2004), serum VEGF-D levels (Young et al., 2013), and bronchodilator responsiveness on spirometry (Taveira-DaSilva et al., 2001).

It has been suggested that patients with TSC-LAM have milder disease and more favorable rate of decline as compared to patients with sporadic LAM (Taveira-DaSilva, PachecoRodriguez, \& Moss, 2010). However, ascertainment bias likely plays a role in this observation as patients with TSC often get diagnosed with LAM at an earlier stage due to screening as compared to patients with sporadic LAM. Further confirmation of this assertion 
is derived from a recently published analysis of the National Heart, Lung, and Blood Institute (NHLBI) intramural cohort where the rate of decline of FEV1 was similar in patients with TSC-LAM and sporadic LAM after matching for baseline disease severity (Taveira-DaSilva et al., 2015).

Survival estimates in LAM are limited, with the most recent studies suggesting a 10-year survival ranging between 76-86\% (Hayashida et al., 2007; Oprescu et al., 2013; Urban et al., 1999), and a median transplant-free survival of 23 years following diagnosis (Oprescu et al., 2013). Various factors have been reported to influence the mortality in patients with LAM; notable being reduced FEV1/FVC ratio (Kitaichi, Nishimura, Itoh, \& Izumi, 1995), worse histology score (Matsui et al., 2001), initial presentation with dyspnea (Hayashida et al., 2007), and the need for supplemental oxygen (Oprescu et al., 2013).

LAM is a significant cause of morbidity and mortality among patients with TSC. In a singlecenter experience with approximately 400 TSC patients, the investigators found that renal involvement was the most common cause of death in patients with TSC, and LAM was a common cause of mortality among adult patients older than 40 years of age. The presence of LAM affected overall mortality; of the patients who had LAM, $40 \%$ (4 out of 10 patients) died, a higher proportion than any other organ involvement from TSC (Shepherd, Gomez, Lie, \& Crowson, 1991). Another recent single-center experience from the UK reported similar findings where renal involvement from TSC was the most common cause of death, and LAM accounted for $12.5 \%$ (2 out of 16) of all TSC-related deaths in this cohort (Amin et al., 2017). In another study, 12.5\% (6 out of 48) of the TSC-LAM patients progressed and died because of LAM (Cudzilo et al., 2013).

\section{Management}

Pharmacological Treatment-The understanding and knowledge about the central role of mTOR pathway activation in the pathogenesis of LAM has transformed the field, and led to the conduct of pivotal trials that form the basis of current pharmacological treatment of LAM. The first study to evaluate the role of the mTORC1 inhibitor, sirolimus in patients with TSC was the Cincinnati Angiomyolipoma Sirolimus Trial (CAST). In this open-label study, 25 patients with TSC were given escalating doses of sirolimus for a period of 12 months followed by drug-free observation for the next 12 months. The mean AML volume decreased by almost $50 \%$ after 12 months of sirolimus treatment; however, the tumors grew back to the baseline volume after stopping sirolimus in the observation year. There were 11 LAM patients in the CAST study, and analysis of PFTs in these patients revealed a significant improvement in the FEV1, forced vital capacity (FVC), and residual volume (RV) following sirolimus administration (Bissler et al., 2008).

Based on these results, the pivotal trial to evaluate the safety of efficacy of mTORC1 inhibition in LAM was conducted, named the Multicenter LAM Efficacy of Sirolimus (MILES) trial. The MILES trial was a randomized, double-blind, placebo-controlled, phase 3 study in which 89 patients with LAM and moderate lung function impairment (defined as post bronchodilator FEV1 $\leq 70 \%$ predicted) were randomized to sirolimus or placebo for 12 months followed by drug-free observation for the next 12 months. The main result of the MILES trial included stabilization in the rate of decline of FEV1 in the sirolimus group as 
compared to the placebo group. In addition, as compared to placebo, the sirolimus group exhibited an improvement in the FVC and some measures of quality of life, as well as a decrease in the serum VEGF-D levels. The FEV1 decline resumed at a rate similar to the placebo group during the observation year, suggesting that the effect of sirolimus is suppressive rather than remission inducing (McCormack et al., 2011).

Similar results demonstrating the safety and efficacy of sirolimus in the treatment of LAM have been obtained in multiple other studies (Takada et al., 2016; Yao et al., 2014). Sirolimus in now approved for use as treatment of LAM by the US Food and Drug Administration (FDA) as well as by regulatory agencies in Japan, South Korea, Brazil, and Russia, and was recently recommended as the first line treatment option for qualifying LAM patients in the LAM clinical practice guidelines (McCormack et al., 2016).

Another mTORC1 inhibitor, everolimus, has been studied more extensively for other TSCrelated manifestations such as AMLs and subependymal giant cell astrocytomas (SEGAs), and is approved by the US FDA for use to treat both of these conditions (Singla, Gupta, Apewokin, \& McCormack, 2017). In a phase II trial of 24 patients with LAM, open label administration of everolimus led to stabilization of FVC, improvement in FEV1 and sixminute walk distance, and had an adverse effect profile consistent with known toxicities of mTOR inhibitors (Goldberg et al., 2015). Although randomized studies of everolimus have not been conducted for patients with LAM, it is reasonable to assume that both drugs will have similar beneficial treatment effects.

Disease Monitoring-Serial measurement of lung function is the cornerstone to monitor disease progression as well as to assess treatment response. Some patients with TSC are unable to perform PFTs due to cognitive difficulties. Currently no reliable biomarkers exist that allow regular monitoring of these patients. Serum VEGF-D levels decrease after treatment with sirolimus and have shown promise as a prognostic and predictive biomarker in LAM (Young et al., 2013). Serial monitoring of serum VEGF-D levels may be an alternative method for longitudinal assessment of disease progression and treatment response in patients who cannot perform PFTs. Other potential biomarkers for this purpose include radiological assessment of disease extent by using chest CT scans (Yao et al., 2014). Further refinement of these biomarkers, and the development of other novel prognostic and predictive biomarkers are critical to effectively monitor LAM patients (Nijmeh, El-Chemaly, \& Henske, 2018).

In addition to monitoring for treatment efficacy, LAM patients on mTOR inhibitors need close monitoring for treatment related adverse effects (AEs). AEs related to mTOR inhibitor use are frequently seen in LAM patients (McCormack et al., 2011), although most AEs tend to be mild, and do not require drug interruption or stoppage. The most common AEs related to use of sirolimus in LAM include stomatitis, acne, hyperlipidemia, nausea, diarrhea, and lower extremity edema (McCormack et al., 2011). Rare but serious AEs related to sirolimus include the development of pneumonitis, infections, and cardiac complications such as pericarditis and atrial arrhythmias (Singla et al., 2017). AEs secondary to sirolimus are most frequent in the first few months following drug initiation, and tend to stabilize over time (Takada et al., 2016). Detailed description of AEs secondary to mTOR inhibitor use, and 
practical tips with regards to the use of sirolimus and management of AEs have recently been published (Singla et al., 2017).

Another question with regards to the use of mTOR inhibitors in LAM relates to the optimal dosing of these drugs. The starting dose of sirolimus in the MILES trial was $2 \mathrm{mg}$ daily, and the dose was titrated to maintain a blood trough level between $5-15 \mathrm{ng} / \mathrm{ml}$ in accordance with the existing renal transplant literature (McCormack et al., 2011). A subsequent retrospective analysis from Japan has suggested that treatment with low dose sirolimus (median dose 1mg daily, average blood trough sirolimus level $2.2 \mathrm{ng} / \mathrm{ml}$ ) may be equally effective in treatment of LAM in this population (Ando et al., 2013). The use of low dose sirolimus for treatment of LAM needs further validation, and is the subject of investigation in an ongoing randomized, double blind, placebo controlled study of women with early-stage LAM (FEV1 $>70 \%$ predicted), named the Multicenter Interventional LAM Early Disease (MILED) trial (NCT03150914).

Air Travel Recommendations-Patients with LAM may be at an increased risk of development of spontaneous pneumothorax due to the increase in cyst size that can occur when exposed to the hypobaric environment of an airplane. The risk of development of spontaneous pneumothorax associated with air travel in LAM has been estimated to be 12\% per 100 flights (Pollock-BarZiv et al., 2007; Taveira-DaSilva et al., 2009). Thus for the majority of LAM patients, it is safe to undertake air travel. Patients should be counseled to seek medical attention and avoid air travel if they experience new or sudden onset dyspnea and/or chest pain characteristic of a pneumothorax prior to boarding the airplane. Although no disease-specific data exists, we advise LAM patients to avoid scuba diving in accordance with the British Thoracic Society guidelines (British Thoracic Society Fitness to Dive Group, 2003).

Vaccinations-Patients with LAM should be encouraged to get vaccinated against influenza (annually) and pneumococcal infections (once with the pneumococcal conjugate vaccine, and every 5 years with the pneumococcal polysaccharide vaccine). In general, patients with LAM who are taking mTOR inhibitors should be educated to avoid taking live vaccinations such as Varicella zoster vaccines (Singla et al., 2017).

\section{Spontaneous Pneumothorax}

Patients with LAM are at a very high risk of experiencing cyst rupture, resulting in the development of spontaneous pneumothorax (Figure 2) (Cooley, Lee, \& Gupta, 2017). The average age at the time of development of spontaneous pneumothorax in LAM is around 35 years (Almoosa et al., 2006). More than 50\% of LAM patients experience at least one spontaneous pneumothorax in their lifetime, with a recurrence rate of approximately $70 \%$ (Almoosa et al., 2006; N. Gupta, Finlay, et al., 2017). Most patients with a sentinel spontaneous pneumothorax experience multiple recurrences with an average of $3.2-5$ pneumothorax episodes per patient (N. Gupta, Finlay, et al., 2017).

Due to the high prevalence of spontaneous pneumothoraces in LAM, all LAM patients should be educated about the signs and symptoms of a pneumothorax, and counseled to seek immediate medical attention in the event of symptoms characteristic of a spontaneous 
pneumothorax (Cooley et al., 2017). Given the high recurrence rate, patients with LAM should be offered pleurodesis following the first episode of spontaneous pneumothorax rather than waiting for a recurrent event. Video-Assisted Thoracoscopic Surgery (VATS)guided mechanical abrasion is the preferred modality for pleurodesis in this population, with more aggressive measures such as talc pleurodesis reserved for refractory or recurrent pneumothoraces (N. Gupta, Finlay, et al., 2017). It is important to note that prior pleurodesis, whether mechanical or talc pleurodesis, is not a contraindication for future lung transplantation (N. Gupta, Finlay, et al., 2017; Weill et al., 2015), and should be offered to all LAM patients with a spontaneous pneumothorax.

\section{Lymphatic manifestations}

The pulmonary lymphatic manifestations of LAM are mainly related to obstruction of the thoracic duct by the LAM cell clusters and subsequent collection of chylous fluid in the pleural cavities (chylothorax) (Figure 2), or rarely chylous lung congestion that may manifest as chyloptysis (Figure 2) (R. Gupta, Kitaichi, Inoue, Kotloff, \& McCormack, 2014; Moua, Olson, Jean, \& Ryu, 2012). Other thoracic lymphatic complications that can occasionally be seen in LAM include mediastinal lymphadenopathy and lymphangioleiomyomas, although these are more commonly seen in the retroperitoneal and pelvic areas (Glasgow, Taveira-Dasilva, Darling, \& Moss, 2008). Chylothorax can be seen in approximately $20-30 \%$ of LAM patients (Moua et al., 2012; Ryu et al., 2006). While the exact prevalence of chylous congestion in LAM is not well established, 7\% of LAM patients were reported to have chyloptysis in a national LAM Registry (Ryu et al., 2006). In general, lymphatic manifestations such as chylous effusions are seen more commonly in patients with sporadic LAM as compared to TSC-LAM (Taveira-DaSilva et al., 2015).

Serum VEGF-D levels are frequently elevated and may be an indicator of lymphatic involvement in LAM patients (Glasgow, Avila, Lin, Stylianou, \& Moss, 2009). Multiple case reports and case series have demonstrated complete or near complete resolution of LAM related chylous collections following administration of sirolimus (Ando et al., 2013; Hecimovic et al., 2015; Taveira-DaSilva, Hathaway, Stylianou, \& Moss, 2011), and sirolimus is now recommended as the treatment of choice for problematic chylous effusions prior to invasive treatment options (McCormack et al., 2016). In severe cases that do not respond to treatment with mTOR inhibition, further management options include pleurodesis, thoracic duct embolization, and thoracic duct ligation. In these situations, an attempt to study the underlying lymphatic anatomy by using dynamic contrast enhanced magnetic resonance lymphangiogram or intranodal lymphangiogram can be helpful in identifying the source of the chyle leak and direct further interventions such as thoracic duct embolization or ligation (Itkin \& McCormack, 2016).

\section{Multifocal Micronodular Pneumocyte Hyperplasia (MMPH)}

MMPH, first described in 1991 (Popper, Juettner-Smolle, \& Pongratz, 1991), refers to benign hamartomatous, nodular proliferation of type II pneumocytes (Muir et al., 1998) (Figure 3). Radiologically, MMPH appears as discrete solid and ground glass nodules, typically ranging between $2-14 \mathrm{~mm}$ in size, with no particular geographic predilection (Muzykewicz et al., 2012) (Figure 3). Although reported in patients with sporadic LAM 
(Muir et al., 1998), MMPH is seen much more commonly in patients with TSC (Franz et al., 2001), and has been suggested to represent an independent feature of TSC (Moss et al., 2001). In contrast to the preferential female involvement of LAM, MMPH can be seen in both men and women with TSC (Moss et al., 2001; Muir et al., 1998). The prevalence of MMPH has been estimated to be around 40-60\% in patients with TSC (Franz et al., 2001; Muzykewicz et al., 2012; Tanaka, Hirata, Wataya-Kaneda, Yoshida, \& Katayama, 2016). However, it is difficult to ascertain the exact prevalence of MMPH in TSC, as the differential diagnosis of nodules is broad, and most TSC patients with nodules are given a presumptive diagnosis of MMPH without undergoing histopathological confirmation. The presence of MMPH has no known physiological or prognostic consequences, with available literature suggesting an overall stable disease course (Konno et al., 2018).

\section{Other pulmonary manifestations of TSC}

There are other pulmonary manifestations that are not mechanistically linked to TSC but can be seen in this population either due to the common nature of these disorders such as asthma, or indirect consequences of TSC such as risk of aspiration events due to TSCrelated seizures or cognitive alterations. Lastly, in the era of mTOR inhibitor therapy for TSC and LAM, clinicians need to be cognizant about the possibility of mTOR inhibitor induced pneumonitis. No cases of drug-induced pneumonitis were reported in the MILES trial (McCormack et al., 2011), but three cases of sirolimus-induced pneumonitis were seen in a Japanese study (Takada et al., 2016). The presentation of mTOR inhibitor induced pneumonitis is very non-specific; patients present with fever, cough, dyspnea, and nonspecific infiltrates on chest imaging. Other etiologies, especially infectious etiologies need to be ruled out prior to establishing a diagnosis of mTOR inhibitor induced pneumonitis, and bronchoscopy may be a useful diagnostic modality in these cases (Champion et al., 2006). It is conceivable that lower doses of mTOR inhibitors typically employed for the treatment of LAM carry a lower risk of inducing pneumonitis than seen in the transplant recipients. However, the relationship between sirolimus dose/trough level and the development of pneumonitis is not well established and needs to be further investigated in large-scale registries and observational trials.

\section{Conclusions}

LAM represents the major form of pulmonary involvement in patients with TSC, and accounts for a significant proportion of morbidity and mortality in this population. Better understanding of the molecular mechanisms driving the disease pathogenesis has ushered an era of targeted treatment, improved patient outcomes, and opened up avenues to develop novel biomarkers and therapies for patients with LAM.

\section{Acknowledgements}

NG received salary support from the NHLBI grant R34HL138235. EPH received funding from NIH U01 HL131022 and The Engles Program in TSC and LAM Research. The authors report no other conflicts of interest pertaining to this manuscript.

Grant Numbers: R34HL138235 (NG), NIH U01 HL131022 and The Engles Program in TSC and LAM Research (EPH). 


\section{Brief Author Bio sketches:}

Nishant Gupta is an Assistant Professor in the Division of Pulmonary, Critical Care and Sleep Medicine at the University of Cincinnati, Cincinnati, $\mathrm{OH}$. He is the director of the rare and interstitial lung disease clinic at the University of Cincinnati, as well as the medical director of the International LAM clinic network. His research is focused on diffuse cystic lung diseases such as LAM, and is aimed at acquiring improved understanding of the natural history, and identifying novel disease-specific diagnostic, prognostic, and predictive biomarkers.

Elizabeth P Henske is the Director of the Center for LAM Research and Clinical Care at Brigham and Women's Hospital, where she has led clinical trials in LAM. She is also Professor of Medicine at Harvard Medical School, an Associate Member of the Broad Institute of MIT and Harvard, and a practicing medical oncologist at the Dana-Farber Cancer Institute. Her research laboratory is focused on the genetic, cellular and metabolic mechanisms underlying the pathogenesis of tuberous sclerosis complex and LAM.

\section{References}

Adriaensen ME, Schaefer-Prokop CM, Duyndam DA, Zonnenberg BA, \& Prokop M (2011). Radiological evidence of lymphangioleiomyomatosis in female and male patients with tuberous sclerosis complex. Clin Radiol, 66(7), 625-628. doi:10.1016/j.crad.2011.02.009 [PubMed: 21459371]

Almoosa KF, Ryu JH, Mendez J, Huggins JT, Young LR, Sullivan EJ, . . Sahn SA (2006). Management of pneumothorax in lymphangioleiomyomatosis: effects on recurrence and lung transplantation complications. Chest, 129(5), 1274-1281. doi:10.1378/chest.129.5.1274 [PubMed: 16685019]

Amin S, Lux A, Calder N, Laugharne M, Osborne J, \& O'Callaghan F (2017). Causes of mortality in individuals with tuberous sclerosis complex. Dev Med Child Neurol, 59(6), 612-617. doi:10.1111/ dmcn.13352 [PubMed: 27935023]

Ando K, Kurihara M, Kataoka H, Ueyama M, Togo S, Sato T, ... Mikami M (2013). Efficacy and safety of low-dose sirolimus for treatment of lymphangioleiomyomatosis. Respir Investig, 51(3), 175-183. doi:10.1016/j.resinv.2013.03.002

Astrinidis A, Khare L, Carsillo T, Smolarek T, Au KS, Northrup H, \& Henske EP (2000). Mutational analysis of the tuberous sclerosis gene TSC2 in patients with pulmonary lymphangioleiomyomatosis. J Med Genet, 37(1), 55-57. [PubMed: 10633137]

Aubry MC, Myers JL, Ryu JH, Henske EP, Logginidou H, Jalal SM, \& Tazelaar HD (2000). Pulmonary lymphangioleiomyomatosis in a man. Am J Respir Crit Care Med, 162(2 Pt 1), 749-752. doi:10.1164/ajrccm.162.2.9911006 [PubMed: 10934115]

Badri KR, Gao L, Hyjek E, Schuger N, Schuger L, Qin W, . . Zhe X (2013). Exonic mutations of TSC2/TSC1 are common but not seen in all sporadic pulmonary lymphangioleiomyomatosis. Am J Respir Crit Care Med, 187(6), 663-665. doi:10.1164/ajrccm.187.6.663 [PubMed: 23504366]

Bissler JJ, McCormack FX, Young LR, Elwing JM, Chuck G, Leonard JM, . . Franz DN (2008). Sirolimus for angiomyolipoma in tuberous sclerosis complex or lymphangioleiomyomatosis. N Engl J Med, 358(2), 140-151. doi:10.1056/NEJMoa063564 [PubMed: 18184959]

British Thoracic Society Fitness to Dive Group, S. o. t. B. T. S. S. o. C. C. (2003). British Thoracic Society guidelines on respiratory aspects of fitness for diving. Thorax, 58(1), 3-13. [PubMed: 12511710]

Cai X, Pacheco-Rodriguez G, Haughey M, Samsel L, Xu S, Wu HP, . . Moss J (2014). Sirolimus decreases circulating lymphangioleiomyomatosis cells in patients with lymphangioleiomyomatosis. Chest, 145(1), 108-112. doi:10.1378/chest.13-1071 [PubMed: 24051985] 
Carsillo T, Astrinidis A, \& Henske EP (2000). Mutations in the tuberous sclerosis complex gene TSC2 are a cause of sporadic pulmonary lymphangioleiomyomatosis. Proc Natl Acad Sci U S A, 97(11), 6085-6090. [PubMed: 10823953]

Champion L, Stern M, Israel-Biet D, Mamzer-Bruneel MF, Peraldi MN, Kreis H, . . Morelon E (2006). Brief communication: sirolimus-associated pneumonitis: 24 cases in renal transplant recipients. Ann Intern Med, 144(7), 505-509. [PubMed: 16585664]

Chang WY, Cane JL, Kumaran M, Lewis S, Tattersfield AE, \& Johnson SR (2014). A 2-year randomised placebo-controlled trial of doxycycline for lymphangioleiomyomatosis. Eur Respir J, 43(4), 1114-1123. doi:10.1183/09031936.00167413 [PubMed: 24311763]

Chilosi M, Pea M, Martignoni G, Brunelli M, Gobbo S, Poletti V, \& Bonetti F (2009). Cathepsin-k expression in pulmonary lymphangioleiomyomatosis. Mod Pathol, 22(2), 161-166. doi:10.1038/ modpathol.2008.189 [PubMed: 19060845]

Cohen MM, Freyer AM, \& Johnson SR (2009). Pregnancy experiences among women with lymphangioleiomyomatosis. Respir Med, 103(5), 766-772. doi:10.1016/j.rmed.2008.11.007 [PubMed: 19117742]

Cooley J, Lee YCG, \& Gupta N (2017). Spontaneous pneumothorax in diffuse cystic lung diseases. Curr Opin Pulm Med, 23(4), 323-333. doi:10.1097/MCP.0000000000000391 [PubMed: 28590337]

Costello LC, Hartman TE, \& Ryu JH (2000). High frequency of pulmonary lymphangioleiomyomatosis in women with tuberous sclerosis complex. Mayo Clin Proc, 75(6), 591-594. doi:10.4065/75.6.591 [PubMed: 10852420]

Cudzilo CJ, Szczesniak RD, Brody AS, Rattan MS, Krueger DA, Bissler JJ, . . Young LR (2013). Lymphangioleiomyomatosis screening in women with tuberous sclerosis. Chest, 144(2), 578-585. doi:10.1378/chest.12-2813 [PubMed: 23539171]

Dabora SL, Jozwiak S, Franz DN, Roberts PS, Nieto A, Chung J, . . Kwiatkowski DJ (2001). Mutational analysis in a cohort of 224 tuberous sclerosis patients indicates increased severity of TSC2, compared with TSC1, disease in multiple organs. Am J Hum Genet, 68(1), 64-80. doi: 10.1086/316951 [PubMed: 11112665]

Dongre A, Clements D, Fisher AJ, \& Johnson SR (2017). Cathepsin K in Lymphangioleiomyomatosis: LAM Cell-Fibroblast Interactions Enhance Protease Activity by Extracellular Acidification. Am J Pathol, 187(8), 1750-1762. doi:10.1016/j.ajpath.2017.04.014 [PubMed: 28623674]

Franz DN, Brody A, Meyer C, Leonard J, Chuck G, Dabora S, . . McCormack FX (2001). Mutational and radiographic analysis of pulmonary disease consistent with lymphangioleiomyomatosis and micronodular pneumocyte hyperplasia in women with tuberous sclerosis. Am J Respir Crit Care Med, 164(4), 661-668. doi:10.1164/ajrccm.164.4.2011025 [PubMed: 11520734]

Glasgow CG, Avila NA, Lin JP, Stylianou MP, \& Moss J (2009). Serum vascular endothelial growth factor-D levels in patients with lymphangioleiomyomatosis reflect lymphatic involvement. Chest, 135(5), 1293-1300. doi:10.1378/chest.08-1160 [PubMed: 19420197]

Glasgow CG, Taveira-Dasilva AM, Darling TN, \& Moss J (2008). Lymphatic involvement in lymphangioleiomyomatosis. Ann N Y Acad Sci, 1131, 206-214. doi:10.1196/annals.1413.018 [PubMed: 18519973]

Goldberg HJ, Harari S, Cottin V, Rosas IO, Peters E, Biswal S, . . Henske EP (2015). Everolimus for the treatment of lymphangioleiomyomatosis: a phase II study. Eur Respir J. doi: $10.1183 / 09031936.00210714$

Goncharova EA, Goncharov DA, Eszterhas A, Hunter DS, Glassberg MK, Yeung RS, ... Krymskaya VP (2002). Tuberin regulates p70 S6 kinase activation and ribosomal protein S6 phosphorylation. A role for the TSC2 tumor suppressor gene in pulmonary lymphangioleiomyomatosis (LAM). $\mathrm{J}$ Biol Chem, 277(34), 30958-30967. doi:10.1074/jbc.M202678200 [PubMed: 12045200]

Gupta N, Finlay GA, Kotloff RM, Strange C, Wilson KC, Young LR, . . Problems, A. T. S. A. o. C. (2017). Lymphangioleiomyomatosis Diagnosis and Management: High-Resolution Chest Computed Tomography, Transbronchial Lung Biopsy, and Pleural Disease Management. An Official American Thoracic Society/Japanese Respiratory Society Clinical Practice Guideline. Am J Respir Crit Care Med, 196(10), 1337-1348. doi:10.1164/rccm.201709-1965ST [PubMed: 29140122] 
Gupta N, Langenderfer D, McCormack FX, Schauer DP, \& Eckman MH (2017). Chest Computed Tomographic Image Screening for Cystic Lung Diseases in Patients with Spontaneous Pneumothorax Is Cost Effective. Ann Am Thorac Soc, 14(1), 17-25. doi:10.1513/AnnalsATS. 201606-459OC [PubMed: 27737563]

Gupta N, Meraj R, Tanase D, James LE, Seyama K, Lynch DA, . . McCormack FX (2015). Accuracy of chest high-resolution computed tomography in diagnosing diffuse cystic lung diseases. Eur Respir J. doi:10.1183/13993003.00570-2015

Gupta N, Vassallo R, Wikenheiser-Brokamp KA, \& McCormack FX (2015). Diffuse Cystic Lung Disease. Part II. Am J Respir Crit Care Med, 192(1), 17-29. doi:10.1164/rccm.201411-2096CI [PubMed: 25906201]

Gupta R, Kitaichi M, Inoue Y, Kotloff R, \& McCormack FX (2014). Lymphatic manifestations of lymphangioleiomyomatosis. Lymphology, 47(3), 106-117. [PubMed: 25420303]

Harari S, Elia D, Torre O, Bulgheroni E, Provasi E, \& Moss J (2016). Sirolimus Therapy for Patients With Lymphangioleiomyomatosis Leads to Loss of Chylous Ascites and Circulating LAM Cells. Chest, 150(2), e29-32. doi:10.1016/j.chest.2016.02.654 [PubMed: 27502989]

Harknett EC, Chang WY, Byrnes S, Johnson J, Lazor R, Cohen MM, . . Johnson SR (2011). Use of variability in national and regional data to estimate the prevalence of lymphangioleiomyomatosis. QJM, 104(11), 971-979. doi:10.1093/qjmed/hcr116 [PubMed: 21764810]

Hayashida M, Seyama K, Inoue Y, Fujimoto K, Kubo K, Respiratory Failure Research Group of the Japanese Ministry of Health, L., \& Welfare. (2007). The epidemiology of lymphangioleiomyomatosis in Japan: a nationwide cross-sectional study of presenting features and prognostic factors. Respirology, 12(4), 523-530. doi:10.1111/j.1440-1843.2007.01101.x [PubMed: 17587419]

Hayashida M, Yasuo M, Hanaoka M, Seyama K, Inoue Y, Tatsumi K, . . Welfare J (2016). Reductions in pulmonary function detected in patients with lymphangioleiomyomatosis: An analysis of the Japanese National Research Project on Intractable Diseases database. Respir Investig, 54(3), 193200. doi:10.1016/j.resinv.2015.11.003

Hecimovic A, Jakopovic M, Pavlisa G, Jankovic M, Vukic-Dugac A, Redzepi G, . . Gupta N (2015). Successful Treatment of Pulmonary and Lymphatic Manifestations of Lymphangioleiomyomatosis with Sirolimus. Lymphology, 48(2), 97-102. [PubMed: 26714374]

Henske EP (2003). Metastasis of benign tumor cells in tuberous sclerosis complex. Genes Chromosomes Cancer, 38(4), 376-381. doi:10.1002/gcc.10252 [PubMed: 14566858]

Henske EP, Jozwiak S, Kingswood JC, Sampson JR, \& Thiele EA (2016). Tuberous sclerosis complex. Nat Rev Dis Primers, 2, 16035. doi:10.1038/nrdp.2016.35 [PubMed: 27226234]

Henske EP, \& McCormack FX (2012). Lymphangioleiomyomatosis - a wolf in sheep's clothing. J Clin Invest, 122(11), 3807-3816. doi:10.1172/JCI58709 [PubMed: 23114603]

Henske EP, Wessner LL, Golden J, Scheithauer BW, Vortmeyer AO, Zhuang Z, . . Yeung RS (1997). Loss of tuberin in both subependymal giant cell astrocytomas and angiomyolipomas supports a two-hit model for the pathogenesis of tuberous sclerosis tumors. Am J Pathol, 151(6), 1639-1647. [PubMed: 9403714]

Itkin M, \& McCormack FX (2016). Nonmalignant Adult Thoracic Lymphatic Disorders. Clin Chest Med, 37(3), 409-420. doi:10.1016/j.ccm.2016.04.004 [PubMed: 27514588]

Johnson SR, Cordier JF, Lazor R, Cottin V, Costabel U, Harari S, . . Review Panel of the, E. R. S. L. A. M. T. F. (2010). European Respiratory Society guidelines for the diagnosis and management of lymphangioleiomyomatosis. Eur Respir J, 35(1), 14-26. doi:10.1183/09031936.00076209 [PubMed: 20044458]

Johnson SR, \& Tattersfield AE (1999). Decline in lung function in lymphangioleiomyomatosis: relation to menopause and progesterone treatment. Am J Respir Crit Care Med, 160(2), 628-633. doi:10.1164/ajrccm.160.2.9901027 [PubMed: 10430739]

Johnson SR, \& Tattersfield AE (2000). Clinical experience of lymphangioleiomyomatosis in the UK. Thorax, 55(12), 1052-1057. [PubMed: 11083892]

Johnson SR, Whale CI, Hubbard RB, Lewis SA, \& Tattersfield AE (2004). Survival and disease progression in UK patients with lymphangioleiomyomatosis. Thorax, 59(9), 800-803. doi: 10.1136/thx.2004.023283 [PubMed: 15333859] 
Jones AC, Shyamsundar MM, Thomas MW, Maynard J, Idziaszczyk S, Tomkins S, . . Cheadle JP (1999). Comprehensive mutation analysis of TSC1 and TSC2-and phenotypic correlations in 150 families with tuberous sclerosis. Am J Hum Genet, 64(5), 1305-1315. doi:10.1086/302381 [PubMed: 10205261]

Karbowniczek M, Astrinidis A, Balsara BR, Testa JR, Lium JH, Colby TV, . . Henske EP (2003). Recurrent lymphangiomyomatosis after transplantation: genetic analyses reveal a metastatic mechanism. Am J Respir Crit Care Med, 167(7), 976-982. doi:10.1164/rccm.200208-969OC [PubMed: 12411287]

Karbowniczek M, Yu J, \& Henske EP (2003). Renal angiomyolipomas from patients with sporadic lymphangiomyomatosis contain both neoplastic and non-neoplastic vascular structures. Am J Pathol, 162(2), 491-500. doi:10.1016/S0002-9440(10)63843-6 [PubMed: 12547707]

Kim NR, Chung MP, Park CK, Lee KS, \& Han J (2003). Pulmonary lymphangioleiomyomatosis and multiple hepatic angiomyolipomas in a man. Pathol Int, 53(4), 231-235. [PubMed: 12675767]

Kitaichi M, Nishimura K, Itoh H, \& Izumi T (1995). Pulmonary lymphangioleiomyomatosis: a report of 46 patients including a clinicopathologic study of prognostic factors. Am J Respir Crit Care Med, 151(2 Pt 1), 527-533. doi:10.1164/ajrccm.151.2.7842216 [PubMed: 7842216]

Konno S, Shigemura M, Ogi T, Shimizu K, Suzuki M, Kaga K, . . Nishimura M (2018). Clinical Course of Histologically Proven Multifocal Micronodular Pneumocyte Hyperplasia in Tuberous Sclerosis Complex: A Case Series and Comparison with Lymphangiomyomatosis. Respiration. doi:10.1159/000486101

Krueger DA, Northrup H, \& International Tuberous Sclerosis Complex Consensus, G. (2013). Tuberous sclerosis complex surveillance and management: recommendations of the 2012 International Tuberous Sclerosis Complex Consensus Conference. Pediatr Neurol, 49(4), 255-265. doi:10.1016/j.pediatrneurol.2013.08.002 [PubMed: 24053983]

Li C, Zhou X, Sun Y, Zhang E, Mancini JD, Parkhitko A, . . Yu JJ (2013). Faslodex inhibits estradiolinduced extracellular matrix dynamics and lung metastasis in a model of lymphangioleiomyomatosis. Am J Respir Cell Mol Biol, 49(1), 135-142. doi:10.1165/rcmb. 2012-0476OC [PubMed: 23526212]

Liu HJ, Lizotte PH, Du H, Speranza MC, Lam HC, Vaughan S, . . Henske EP (2018). TSC2-deficient tumors have evidence of T cell exhaustion and respond to anti-PD-1/anti-CTLA-4 immunotherapy. JCI Insight, 3(8). doi:10.1172/jci.insight.98674

Logginidou H, Ao X, Russo I, \& Henske EP (2000). Frequent estrogen and progesterone receptor immunoreactivity in renal angiomyolipomas from women with pulmonary lymphangioleiomyomatosis. Chest, 117(1), 25-30. [PubMed: 10631194]

Matsui K, Beasley MB, Nelson WK, Barnes PM, Bechtle J, Falk R, . . Travis WD (2001). Prognostic significance of pulmonary lymphangioleiomyomatosis histologic score. Am J Surg Pathol, 25(4), 479-484. [PubMed: 11257622]

Matsui K, Takeda K, Yu ZX, Travis WD, Moss J, \& Ferrans VJ (2000). Role for activation of matrix metalloproteinases in the pathogenesis of pulmonary lymphangioleiomyomatosis. Arch Pathol Lab Med, 124(2), 267-275. doi:10.1043/0003-9985(2000)124<0267:RFAOMM>2.0.CO;2 [PubMed: 10656737]

McCormack FX, Gupta N, Finlay GR, Young LR, Taveira-DaSilva AM, Glasgow CG, .. . Lymphangioleiomyomatosis, A. J. C. o. (2016). Official American Thoracic Society/Japanese Respiratory Society Clinical Practice Guidelines: Lymphangioleiomyomatosis Diagnosis and Management. Am J Respir Crit Care Med, 194(6), 748-761. doi:10.1164/rccm.201607-1384ST [PubMed: 27628078]

McCormack FX, Inoue Y, Moss J, Singer LG, Strange C, Nakata K, . . Group MT (2011). Efficacy and safety of sirolimus in lymphangioleiomyomatosis. N Engl J Med, 364(17), 1595-1606. doi: 10.1056/NEJMoa1100391 [PubMed: 21410393]

McCormack FX, Travis WD, Colby TV, Henske EP, \& Moss J (2012). Lymphangioleiomyomatosis: calling it what it is: a low-grade, destructive, metastasizing neoplasm. Am J Respir Crit Care Med, 186(12), 1210-1212. doi:10.1164/rccm.201205-0848OE [PubMed: 23250499]

Miyake M, Tateishi U, Maeda T, Kusumoto M, Satake M, Arai Y, \& Sugimura K (2005). Pulmonary lymphangioleiomyomatosis in a male patient with tuberous sclerosis complex. Radiat Med, 23(7), 525-527. [PubMed: 16485546] 
Moses MA, Harper J, \& Folkman J (2006). Doxycycline treatment for lymphangioleiomyomatosis with urinary monitoring for MMPs. N Engl J Med, 354(24), 2621-2622. doi:10.1056/ NEJMc053410 [PubMed: 16775248]

Moss J, Avila NA, Barnes PM, Litzenberger RA, Bechtle J, Brooks PG, . . Kristof AS (2001). Prevalence and clinical characteristics of lymphangioleiomyomatosis (LAM) in patients with tuberous sclerosis complex. Am J Respir Crit Care Med, 164(4), 669-671. doi:10.1164/ajrccm. 164.4.2101154 [PubMed: 11520735]

Moua T, Olson EJ, Jean HC, \& Ryu JH (2012). Resolution of chylous pulmonary congestion and respiratory failure in lymphangioleiomyomatosis with sirolimus therapy. Am J Respir Crit Care Med, 186(4), 389-390. doi:10.1164/ajrccm.186.4.389 [PubMed: 22896596]

Muir TE, Leslie KO, Popper H, Kitaichi M, Gagne E, Emelin JK, . . Colby TV (1998). Micronodular pneumocyte hyperplasia. Am J Surg Pathol, 22(4), 465-472. [PubMed: 9537475]

Muzykewicz DA, Black ME, Muse V, Numis AL, Rajagopal J, Thiele EA, \& Sharma A (2012). Multifocal micronodular pneumocyte hyperplasia: computed tomographic appearance and followup in tuberous sclerosis complex. J Comput Assist Tomogr, 36(5), 518-522. doi:10.1097/RCT. 0b013e318264e404 [PubMed: 22992599]

Muzykewicz DA, Sharma A, Muse V, Numis AL, Rajagopal J, \& Thiele EA (2009). TSC1 and TSC2 mutations in patients with lymphangioleiomyomatosis and tuberous sclerosis complex. J Med Genet, 46(7), 465-468. doi:10.1136/jmg.2008.065342 [PubMed: 19419980]

Niida Y, Stemmer-Rachamimov AO, Logrip M, Tapon D, Perez R, Kwiatkowski DJ, . . Ramesh V (2001). Survey of somatic mutations in tuberous sclerosis complex (TSC) hamartomas suggests different genetic mechanisms for pathogenesis of TSC lesions. Am J Hum Genet, 69(3), 493-503. doi:10.1086/321972 [PubMed: 11468687]

Nijmeh J, El-Chemaly S, \& Henske EP (2018). Emerging biomarkers of lymphangioleiomyomatosis. Expert Rev Respir Med, 12(2), 95-102. doi:10.1080/17476348.2018.1409622 [PubMed: 29171770]

Oprescu N, McCormack FX, Byrnes S, \& Kinder BW (2013). Clinical predictors of mortality and cause of death in lymphangioleiomyomatosis: a population-based registry. Lung, 191(1), 35-42. doi:10.1007/s00408-012-9419-3 [PubMed: 23007140]

Osterburg AR, Nelson RL, Yaniv BZ, Foot R, Donica WR, Nashu MA, . . Borchers MT (2016). NK cell activating receptor ligand expression in lymphangioleiomyomatosis is associated with lung function decline. JCI Insight, 1(16), e87270. doi:10.1172/jci.insight.87270 [PubMed: 27734028]

Pollock-BarZiv S, Cohen MM, Downey GP, Johnson SR, Sullivan E, \& McCormack FX (2007). Air travel in women with lymphangioleiomyomatosis. Thorax, 62(2), 176-180. doi:10.1136/thx. 2006.058537 [PubMed: 17040934]

Popper HH, Juettner-Smolle FM, \& Pongratz MG (1991). Micronodular hyperplasia of type II pneumocytes--a new lung lesion associated with tuberous sclerosis. Histopathology, 18(4), 347354. [PubMed: 2071093]

Prizant H, Sen A, Light A, Cho SN, DeMayo FJ, Lydon JP, \& Hammes SR (2013). Uterine-specific loss of Tsc2 leads to myometrial tumors in both the uterus and lungs. Mol Endocrinol, 27(9), 1403-1414. doi:10.1210/me.2013-1059 [PubMed: 23820898]

Ryu JH, Moss J, Beck GJ, Lee JC, Brown KK, Chapman JT, . . Group NLR (2006). The NHLBI lymphangioleiomyomatosis registry: characteristics of 230 patients at enrollment. Am J Respir Crit Care Med, 173(1), 105-111. doi:10.1164/rccm.200409-1298OC [PubMed: 16210669]

Ryu JH, Sykes AM, Lee AS, \& Burger CD (2012). Cystic lung disease is not uncommon in men with tuberous sclerosis complex. Respir Med, 106(11), 1586-1590. doi:10.1016/j.rmed.2012.07.007 [PubMed: 22871462]

Sato T, Seyama K, Fujii H, Maruyama H, Setoguchi Y, Iwakami S, . . Hino O (2002). Mutation analysis of the TSC1 and TSC2 genes in Japanese patients with pulmonary lymphangioleiomyomatosis. J Hum Genet, 47(1), 20-28. doi:10.1007/s10038-002-8651-8 [PubMed: 11829138]

Schiavina M, Di Scioscio V, Contini P, Cavazza A, Fabiani A, Barberis M, ... D’Errico-Grigioni A (2007). Pulmonary lymphangioleiomyomatosis in a karyotypically normal man without tuberous 
sclerosis complex. Am J Respir Crit Care Med, 176(1), 96-98. doi:10.1164/rccm.200610-1408CR [PubMed: 17431222]

Shepherd CW, Gomez MR, Lie JT, \& Crowson CS (1991). Causes of death in patients with tuberous sclerosis. Mayo Clin Proc, 66(8), 792-796. [PubMed: 1861550]

Singla A, Gupta N, Apewokin S, \& McCormack FX (2017). Sirolimus for the treatment of lymphangioleiomyomatosis. Expert Opinion on Orphan Drugs, 5(11), 907-921. doi: 10.1080/21678707.2017.1391089

Strizheva GD, Carsillo T, Kruger WD, Sullivan EJ, Ryu JH, \& Henske EP (2001). The spectrum of mutations in TSC1 and TSC2 in women with tuberous sclerosis and lymphangiomyomatosis. Am J Respir Crit Care Med, 163(1), 253-258. doi:10.1164/ajrccm.163.1.2005004 [PubMed: 11208653]

Suzuki K, Nagasaka K, Oda K, Abe H, Maeda D, Matsumoto Y, . . Fujii T (2016). A case of lymphangioleiomyomatosis associated with endometrial cancer and severe systemic lupus erythematosus. BMC Cancer, 16, 390. doi:10.1186/s12885-016-2413-z [PubMed: 27377753]

Takada T, Mikami A, Kitamura N, Seyama K, Inoue Y, Nagai K, ... Nakata K (2016). Efficacy and Safety of Long-Term Sirolimus Therapy for Asian Patients with Lymphangioleiomyomatosis. Ann Am Thorac Soc, 13(11), 1912-1922. doi:10.1513/AnnalsATS.201605-335OC [PubMed: 27513278]

Tanaka M, Hirata H, Wataya-Kaneda M, Yoshida M, \& Katayama I (2016). Lymphangioleiomyomatosis and multifocal micronodular pneumocyte hyperplasia in Japanese patients with tuberous sclerosis complex. Respir Investig, 54(1), 8-13. doi:10.1016/j.resinv. 2015.06.003

Taveira-DaSilva AM, Burstein D, Hathaway OM, Fontana JR, Gochuico BR, Avila NA, \& Moss J (2009). Pneumothorax after air travel in lymphangioleiomyomatosis, idiopathic pulmonary fibrosis, and sarcoidosis. Chest, 136(3), 665-670. doi:10.1378/chest.08-3034 [PubMed: 19318672]

Taveira-DaSilva AM, Hathaway O, Stylianou M, \& Moss J (2011). Changes in lung function and chylous effusions in patients with lymphangioleiomyomatosis treated with sirolimus. Ann Intern Med, 154(12), 797-805, W-292-793. doi:10.7326/0003-4819-154-12-201106210-00007 [PubMed: 21690594]

Taveira-DaSilva AM, Hedin C, Stylianou MP, Travis WD, Matsui K, Ferrans VJ, \& Moss J (2001). Reversible airflow obstruction, proliferation of abnormal smooth muscle cells, and impairment of gas exchange as predictors of outcome in lymphangioleiomyomatosis. Am J Respir Crit Care Med, 164(6), 1072-1076. doi:10.1164/ajrccm.164.6.2102125 [PubMed: 11587999]

Taveira-DaSilva AM, Jones AM, Julien-Williams P, Yao J, Stylianou M, \& Moss J (2015). Severity and outcome of cystic lung disease in women with tuberous sclerosis complex. Eur Respir J, 45(1), 171-180. doi:10.1183/09031936.00088314 [PubMed: 25537563]

Taveira-DaSilva AM, Pacheco-Rodriguez G, \& Moss J (2010). The natural history of lymphangioleiomyomatosis: markers of severity, rate of progression and prognosis. Lymphat Res Biol, 8(1), 9-19. doi:10.1089/lrb.2009.0024 [PubMed: 20235883]

Taveira-DaSilva AM, Stylianou MP, Hedin CJ, Hathaway O, \& Moss J (2004). Decline in lung function in patients with lymphangioleiomyomatosis treated with or without progesterone. Chest, 126(6), 1867-1874. doi:10.1378/chest.126.6.1867 [PubMed: 15596686]

Urban T, Lazor R, Lacronique J, Murris M, Labrune S, Valeyre D, \& Cordier JF (1999). Pulmonary lymphangioleiomyomatosis. A study of 69 patients. Groupe d'Etudes et de Recherche sur les Maladies “Orphelines” Pulmonaires (GERM”O”P). Medicine (Baltimore), 78(5), 321-337. [PubMed: 10499073]

Weill D, Benden C, Corris PA, Dark JH, Davis RD, Keshavjee S, . . Glanville AR (2015). A consensus document for the selection of lung transplant candidates: 2014--an update from the Pulmonary Transplantation Council of the International Society for Heart and Lung Transplantation. J Heart Lung Transplant, 34(1), 1-15. doi:10.1016/j.healun.2014.06.014 [PubMed: 25085497]

Yano S (2002). Exacerbation of pulmonary lymphangioleiomyomatosis by exogenous oestrogen used for infertility treatment. Thorax, 57(12), 1085-1086. [PubMed: 12454306]

Yao J, Taveira-DaSilva AM, Jones AM, Julien-Williams P, Stylianou M, \& Moss J (2014). Sustained effects of sirolimus on lung function and cystic lung lesions in lymphangioleiomyomatosis. Am J 
Respir Crit Care Med, 190(11), 1273-1282. doi:10.1164/rccm.201405-0918OC [PubMed: 25329516]

Yockey CC, Riepe RE, \& Ryan K (1986). Pulmonary lymphangioleiomyomatosis complicated by pregnancy. Kans Med, 87(10), 277-278, 293. [PubMed: 3807098]

Young L, Lee HS, Inoue Y, Moss J, Singer LG, Strange C, . . Group MT (2013). Serum VEGF-D a concentration as a biomarker of lymphangioleiomyomatosis severity and treatment response: a prospective analysis of the Multicenter International Lymphangioleiomyomatosis Efficacy of Sirolimus (MILES) trial. Lancet Respir Med, 1(6), 445-452. doi:10.1016/S2213-2600(13)70090-0 [PubMed: 24159565]

Yu J, Astrinidis A, \& Henske EP (2001). Chromosome 16 loss of heterozygosity in tuberous sclerosis and sporadic lymphangiomyomatosis. Am J Respir Crit Care Med, 164(8 Pt 1), 1537-1540. doi: 10.1164/ajrccm.164.8.2104095 [PubMed: 11704609]

Yu J, Astrinidis A, Howard S, \& Henske EP (2004). Estradiol and tamoxifen stimulate LAMassociated angiomyolipoma cell growth and activate both genomic and nongenomic signaling pathways. Am J Physiol Lung Cell Mol Physiol, 286(4), L694-700. doi:10.1152/ajplung. 00204.2003 [PubMed: 12922981]

Yu JJ, Robb VA, Morrison TA, Ariazi EA, Karbowniczek M, Astrinidis A, . . Henske EP (2009). Estrogen promotes the survival and pulmonary metastasis of tuberin-null cells. Proc Natl Acad Sci U S A, 106(8), 2635-2640. doi:10.1073/pnas.0810790106 [PubMed: 19202070] 

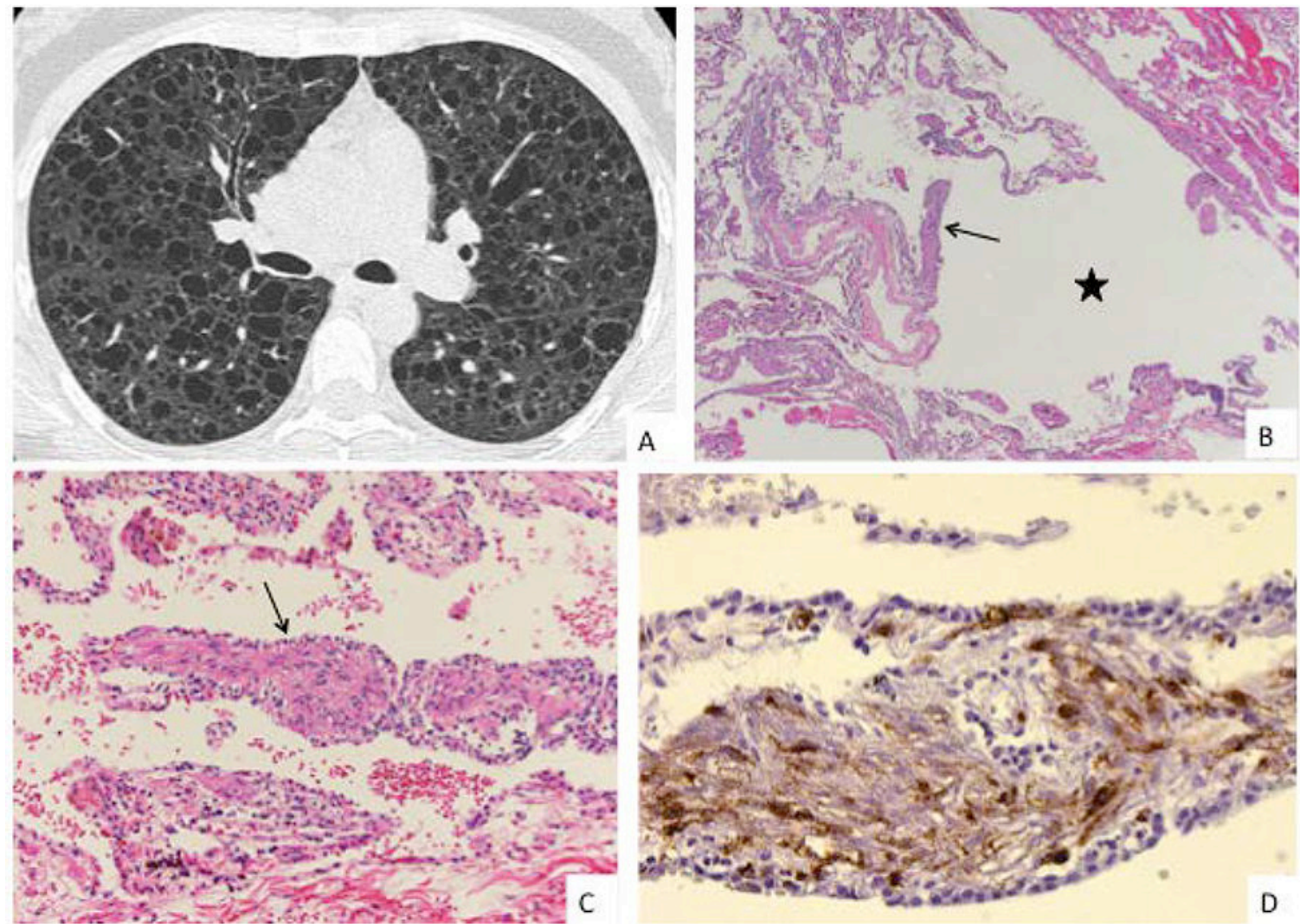

Figure 1. :Radiological and histopathological features of LAM.

1A: High-resolution chest CT images from a patient with LAM demonstrating the characteristic thin-walled, round, uniform cysts. 1B: Histopathology demonstrating a cystic air filled space (star) lined by LAM cells (arrow). 1C: High-power view demonstrating the LAM cells surrounding the cystic space. Notice the characteristic epitheloid and spindle shaped morphology of these cells. These cells stained positive for smooth muscle cell markers (stains not shown) as well as HMB-45 (1D). Histopathological images courtesy of Dani S. Zander, MD at the University of Cincinnati. 

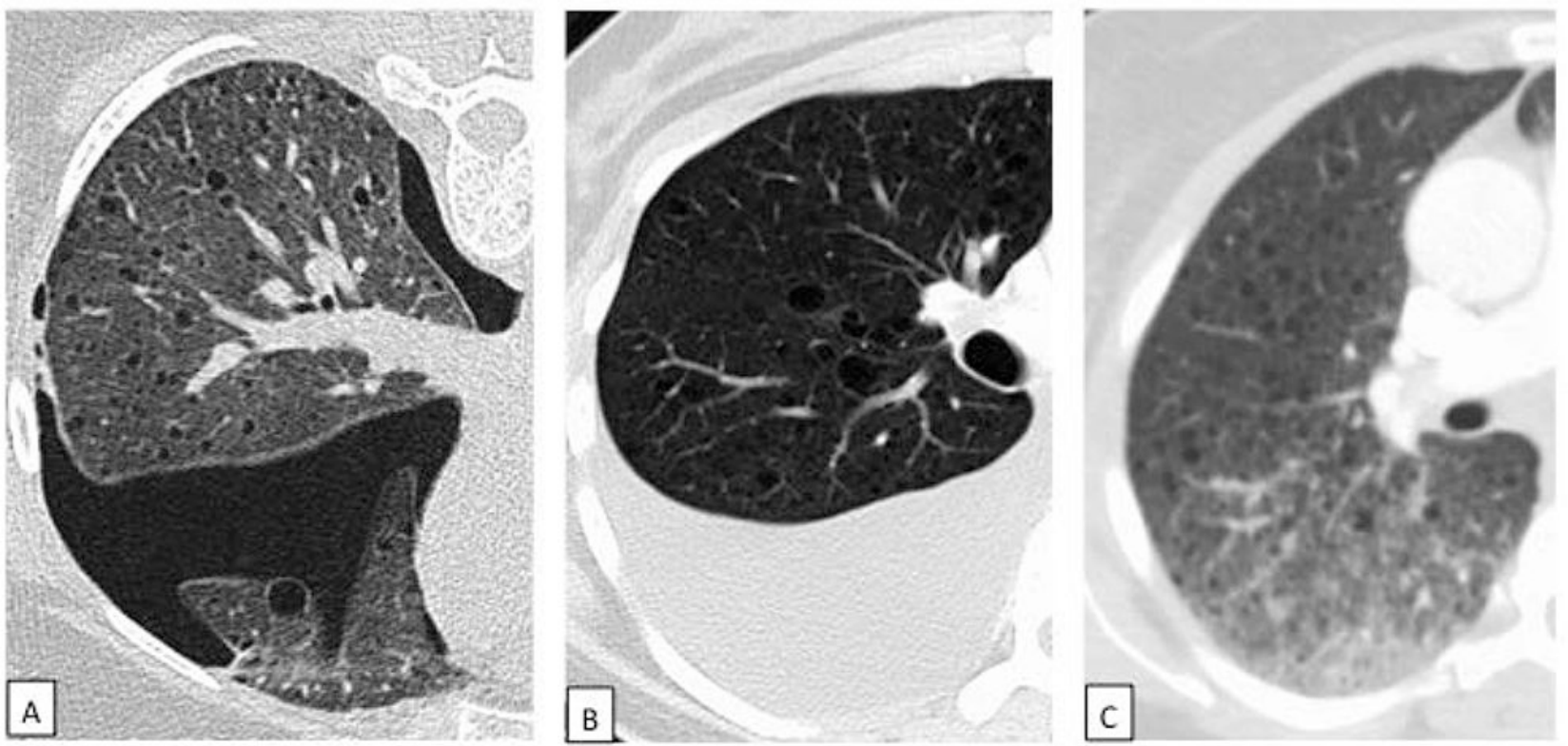

Figure 2. : Pleural and lymphatic involvement in LAM.

2A: CT chest in a patient with TSC-LAM showing a spontaneous pneumothorax. 2B: CT chest demonstrating right sided pleural effusion that was confirmed as a chylothorax following thoracentesis. $2 \mathrm{C}$ : $\mathrm{CT}$ chest showing ground glass attenuation in the right lower lobe suggestive of chylous congestion in a patient with LAM and history of chyloptysis. 2B and $2 \mathrm{C}$ : The chylous effusion as well as the chylous congestion resolved successfully after treating with sirolimus. 

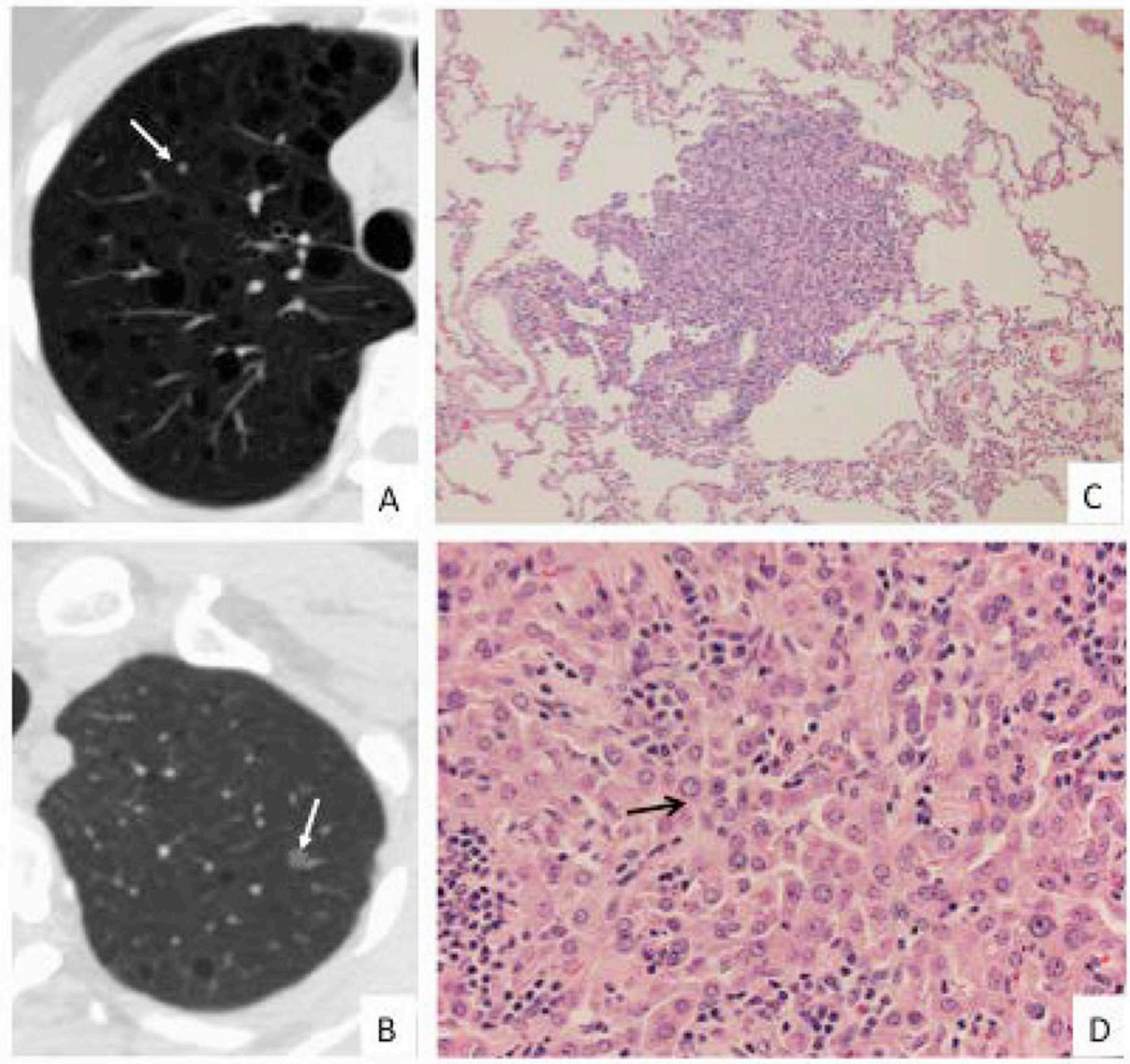

Figure 3. :Radiological and histopathological features of MMPH.

3A and B: CT scan images from two patients with TSC-LAM showing characteristic nodular densities (arrow) seen in MMPH. 3C and D: Histopathology showing nodular collection of alveolar type II pneumocytes in low power (3C) and high power views (3D, arrow) characteristic of MMPH. Histopathological images courtesy of Dani S. Zander, MD at the University of Cincinnati. 
Table 1:

Salient features of TSC-LAM and sporadic LAM

\begin{tabular}{|l|l|l|}
\hline Characteristic & TSC-LAM & Sporadic LAM \\
\hline Prevalence & More common & Less common \\
\hline TSC mutations & Both TSC1 and TSC2 & Only $T S C 2^{*}$ \\
\hline Reported in males & Yes & Extremely rare \\
\hline Most common mode of ascertainment & Screening & Dyspnea \\
\hline Inheritable & Yes & No \\
\hline Renal AMLs & $90 \%$ & $30 \%$ \\
\hline Lymphangioleiomyomas & $10 \%$ & $30 \%$ \\
\hline MMPH & $\sim 40 \%$ & Very rare \\
\hline
\end{tabular}

* TSC1 mutations have rarely been reported in patents with sporadic LAM (Sato et al., 2002)

Abbreviations: $\mathrm{AML}=$ Angiomyolipoma, $\mathrm{LAM}=$ Lymphangioleiomyomatosis, $\mathrm{MMPH}=$ Multifocal micronodular pneumocyte hyperplasia, $\mathrm{TSC}$ $=$ Tuberous sclerosis complex. 
Table 2:

Checklist of management and healthcare maintenance tasks for patients diagnosed with LAM

\begin{tabular}{|l|l|}
\hline Category & Tasks \\
\hline \multirow{5}{*}{ Disease monitoring } & Screening HRCT at age 18 for patients with TSC \\
\cline { 2 - 3 } & PFTs every 3-6 months (in patients with confirmed LAM) to establish trajectory of disease progression \\
\cline { 2 - 3 } Drug monitoring & $\begin{array}{l}\text { Baseline serum VEGF-D. Consider repeating at annual intervals, especially in patients who can't perform } \\
\text { PFTs }\end{array}$ \\
\cline { 2 - 3 } & $\begin{array}{l}\text { Start mTOR inhibitors for patients with abnormal lung function (FEV1 < 70\%), problematic chylous } \\
\text { effusions, rapidly declining patients, and patients with significant disease burden as assessed by cyst profusion } \\
\text { on HRCT chest, need for supplemental oxygen, abnormal DLCO and/or air trapping on PFTs. }\end{array}$ \\
\hline & PFTs every 3-6 months post drug initiation to monitor treatment response \\
\cline { 2 - 3 } & Baseline CBC, CMP, Lipid panel, and urinalysis \\
\cline { 2 - 3 } Other healthcare maintenance & Repeat safety labs every month for the first 3 months followed by every 3 month lab checks \\
\cline { 2 - 3 } & Caution about sun protection \\
\cline { 2 - 3 } & Monitor for signs and symptoms of pneumonitis \\
\hline & Pneumococcal vaccination and annual Influenza vaccination \\
\cline { 2 - 3 } & Avoid live vaccines in patients taking mTOR inhibitors \\
\cline { 2 - 3 } & Pneumothorax action plan (symptoms to recognize, pleurodesis after first event) \\
\cline { 2 - 3 } & Reassure regarding safety of air travel, counsel to avoid scuba diving \\
\hline
\end{tabular}

Abbreviations: See Table 1 plus, $\mathrm{CBC}=$ complete blood count, $\mathrm{CMP}=$ comprehensive metabolic panel, $\mathrm{DLCO}=$ diffusing capacity of the lung for carbon monoxide, FEV1 = forced expiratory volume in one-second, HRCT $=$ high-resolution computed tomography, $\mathrm{mTOR}=$ mechanistic target of rapamycin, PFTs = pulmonary function tests. 